\title{
Work Motivation of Bus Workers Bangkok File Company Limited
}

\author{
Dr. Watchara Yeesoontes and Pichapat Kaewcha
}

\begin{abstract}
The purpose of this study was to investigate the level of job satisfaction and to investigate the motivation of employees in the Bangkok File Services Quantitative study The study population consisted of 310 employees. The questionnaire was used as a tool for the study. Statistics used in data analysis were descriptive statistics, frequency, percentage, mean, standard deviation, one-way ANOVA, Correlation and Regression Analysis. The study found that the majority of respondents were female, aged 26-30 years, single status, education, bachelor's degree, occupational employment, 2-5 years of employment, and average monthly income. 20,001-25,000 Baht Factors affecting the motivation of the employees in the passenger section of Bangkok File Services Co., Ltd. are summarized as follows: Responsibility The success of the operation. Control and control Security in the job. The nature of the work. Relationships with bosses and colleagues. Work environment To be respected. Compensation and the progress in the job
\end{abstract}

\section{Keywords - Work Motivation, Company}

\section{INTRODUCTION}

Suggestions from the study results. Executives should pay attention to the compensation, benefits, benefits and benefits of the employees, taking into account the safety of the employees. And should give the opportunity to promote because it is a good morale for employees who are committed and dedicated to work.

Air Transport Business or Aviation Business It is one of the components of the aviation industry. The airline business can be individual or juristic person. There are two types of types. The airline business that passenger business. And the second type is the air cargo shipping business operators. It is considered as a gathering of factors such as aircraft, routes, capital, labor, etc. With the use of airport services. As a result, the aviation business is a popular business with a large number of passengers. Due to fast travel, it is safe. Can transport passengers or goods in large quantities. And in the aviation business, there will be various airline companies. To replace the airline in ground service, both in the area of the landing and the passenger service, so they have to be motivated to work. At Suvarnabhumi Airport, there are various services such as ground services in the passenger terminal. Airport services in various airlines. The landlord and other services. Bangkok File

F. A. Author is with the National Institute of Standards and Technology, Boulder, CO 80305 USA

S. B. Author was with Rice University, Houston, TX 77005 USA. He is now with the Department of Physics, Colorado State University, Fort Collins, CO 80523 USA
Services Co., Ltd. is one of the airline companies providing ground services in both the parking lot and the passenger section of Suvarnabhumi Airport. Therefore, the personnel is important in the operation to achieve the organization. Set goals

Bangkok File Services also provides operational management services to various airlines, covering operations in all service sectors in the aviation sector. Including the services of the passenger section. When the organization came to work. Expect the employees to grow. It is a progressive and important force of the organization in the future. There are many different types of fare. There is also a difference in performance as well. The employees in the passenger section need to study. And to learn in the work, have knowledge, ability to perform. This can affect customer satisfaction and create a positive image for the organization. Employees need motivation to work. To be able to work fully or to be active in the work. This will result in quality work. And can meet the needs of the organization. If the employee does not have motivation to work. It may result in a poor quality of work. The company loses opportunities and disadvantages competitors. It can lead to failure of the organization.

For the reasons mentioned above. The study is one of the Company's personnel. Therefore, it is necessary to study the motivation of the employees in Bangkok Passenger Service Co., Ltd. The results obtained from the study will be useful in the information as a guideline. Motivation in the performance of employees. This will lead to the improvement and development of personnel management of the company. In the work of the employees.

\section{PURPOSE OF STUDY}

To study the level of satisfaction of the employees of the passenger bus. Bangkok Files Company Limited

-To study the motivation that affects the job satisfaction of the employees of the Bangkok Lotte Service Co., Ltd.

\section{ASSUMPTIONS OF THE STUDY}

Different personal factors have different effects on the job satisfaction of the employees of Bangkok File Services Co., Ltd. Motivation correlated with job satisfaction of bus drivers. Bangkok File Company Limited. Motivation Affecting Job Satisfaction of Bus Workers Bangkok File Company Limited 


\section{SCOPE OF STUDY}

The content of the study was to study the factors affecting the motivation of the employees of Bangkok File Services Co., Ltd., based on Frederick Herzberg's two-factor theory, consisting of motivating factors and supporting factors. Population and sample used in the study. The population used in the study is There were 1,236 volunteers in 255 file services in Bangkok, with 310 samples selected. The duration of study is from November 2016 to January 2017.

\section{THE BENEFITS OF THE STUDY}

The level of satisfaction of the employees of the company. Bangkok File Service Factors influencing job satisfaction of the employees of the Bangkok Lotte Service Co., Ltd. Bring the information that is used as a guideline to motivate the performance of the travel staff to perform better.

\section{MOTIVATION THEORY}

The two-factor theory of Frederick Herzberg Herzberg
(Herzberg, 1959) has proposed two theories. To be involved in the operation. In summary, there are two important factors that are relevant to the individual's likes and dislikes. The factor is.

Motivation factor Recognize the ability to work successfully. Acceptance will be latent with success in the work. Hygiene factor, sustainability factors or hygiene factors are factors that will sustain. The motivation for the work of people who are always available. If there are characteristics that are not consistent with the person in the organization. People in the organization will be dissatisfied or dissatisfied in the work. It consists of a frame.

\section{CONCEPTS IN EDUCATION}

The study on motivation of the employees of the Bangkok Lotte Service Co., Ltd The study is summarized and co-ordinated as a framework for the study as shown in the picture.

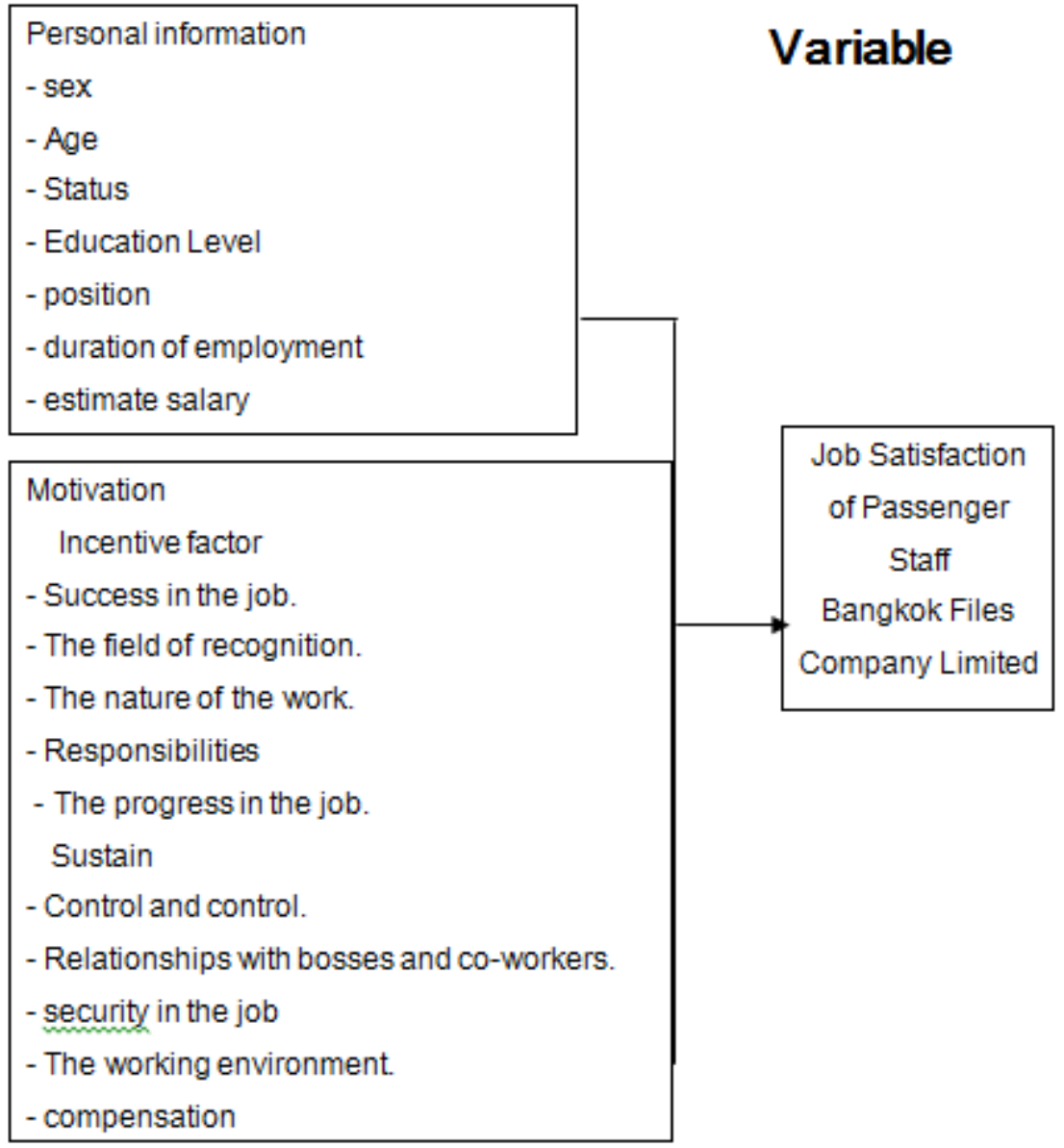




\section{RESOURCES USED IN THE STUDY}

There are two main sources of data for this study: primary data, secondary data, Population sample used in the study.

The sample size was 310 samples. In the study, the sample size was (Simple size) using the Taro Yamanote formula (Yamane, Taro, 1967: 56) at a 95\% confidence level or 0.05 error using the formula: There were 302 samples in this study. The study population consisted of 310 samples.

\section{CONCLusion}

A study on the motivation of the employees of Bangkok File Services Co., Ltd. to study the level of job satisfaction of the employees of Bangkok File Services Co., Ltd. The satisfaction of the employees of the passenger service department of Bangkok File Services Co., Ltd. to be used in enhancing the Performance of staff to passengers of Bangkok File Services Limited is a way to study the quantitative study. Quantitative Research. The population consisted of 310 employees of Bangkok File Services Co., Ltd. The variables were sex, age, status, education level, job position, average age, and income. The questionnaire consists of: The questionnaire was used as a tool for the study. The statistics used were percentage, mean, standard deviation One-Way ANOVA Correlation and Regression Analysis

\section{FACTORS AFFECTING Job Motivation}

A study of factors affecting the motivation of employees in the passenger sector. Bangkok File Services Co., Ltd. Sort by priority to descending order is the responsibility. The success of the operation. Controlling and controlling security in the workplace. Relationships with bosses and colleagues in the workplace environment. To be respected. Compensation And the progress in the job. The details are as follows

\section{THE SUCCESS OF THE OPERATION}

The results showed that the success of the operation. At the high level of the 3 items, the average order from the most to the least is the ability to work successfully to meet the target can solve problems in the work well. Be proud of being part of the success of the event. Overall, factors affecting job motivation. The success of the operation. Very high

\section{TO BE RESPECTED}

The study found that the aspects of being respected. At the high level of the 3 items, the average order from the most to the least is a matter of recognition from colleagues. Honorable work Dignity in the profession Recognized for the success of the work. Overall, factors affecting job motivation. To be respected. Very high.

\section{THE NATURE OF THE WORK}

The results show that the characteristics of the work. In the three levels, the average order from the most to the least is the satisfaction with the job. The job done requires knowledge. And ability Job description is important and challenging. Overall, factors affecting job motivation. The nature of the work. Very high Responsibility

The study found that the responsibility. In the three levels, the average order from the most to the least is the assigned task at full capacity. Trust and trust in responsible work. And the appropriateness of the workload and the number of people responsible. Overall, factors affecting job motivation. Responsibility Very high

\section{THE PROGRESS IN THE JOB}

The results show that the progress in the job. In the second level, the average order is as follows: There is a chance to postpone the job. And think that the practice is more likely to progress. In the medium level, one of the subjects was encouraged to develop knowledge, abilities, such as the quality of life. The progress in the job. Very high Control and control The results showed that.

\section{MANAGEMENT AND CONTROL}

At the high level of the 3 items, the average order from the most to the least is the supervisor has the ability to manage. Supervisors are clear in their job assignments and assignments. And the bosses are fair in the assignment. Overall, factors affecting job motivation. Control and control Very high

\section{RELATIONSHIPS WITH BOSSES AND COLLEAGUES}

The study found that relationships with bosses and colleagues At the high level of the 3 items, the average order from the least to the most is the work with supervisors and colleagues as well. Colleagues contribute to encouraging the work. And bosses listen to the problem. Comments and suggestions Willingly Overall, factors affecting job motivation. Relationships with bosses and colleagues. Very high

\section{SECURITY IN THE JOB}

The results show that the security of the job. At the high level of the three stories, the average order from the most to the least is the company reputation and good image reliability. The company is more stable than any other company. And the company has the honor and pride. Overall, factors affecting job motivation. Security in the job. Very high

\section{WORK ENVIRONMENT}

The study found that the work environment. In the three levels of the ranking, the average is as follows: physical environment, location, weather, lighting are appropriate. The facility is safe in life and property. And agencies have enough work facilities. Overall, factors affecting job motivation. Work environment Very high 


\section{COMPENSATION}

The results show that the compensation. In the second level, the average level of descent is as follows: welfare and benefits. Appropriate And satisfied with the salary received. 1 is the subject of a fair salary upgrade. Overall, factors affecting job motivation. Compensation Very high

\section{JOB SATISFACTION}

As a result, the level of job satisfaction of the employees of Bangkok File Services Co., Ltd. showed that employees had a high level of job satisfaction.

\section{DISCUSSIONS}

The study of the motivation of the employees of the Bangkok File Services division showed that the success of the operation. To be respected. The nature of the work. Responsibility The progress in the job. Control and control Relationships with supervisors and colleagues. Security in the job. Work environment Compensation levels are at a high level. This is consistent with research by patomvong srihsana (2557). The motivation in working of the staff of Camp Nong Kwang Subdistrict, Bangka Subdistrict, Muang District, Chanthaburi Province. The results of the study showed that the overall motivation for motivation was motivation at the high level. The study of success in the workplace is at a high level. This is consistent with the research by tosaporn mahamud (2558), which studies the motivational factors affecting the performance of employees in the Big Lottery Factory. The success of the operation. Very high The study on the acceptance of respect at a high level. This is in line with Sujari Jang Mongkol's (2558) study on the motivation of the employees of AirAsia Co., Ltd. Very high

\section{RECOMMENDATIONS FROM THE STUDY.}

The study of motivation in the operation of the employees of the Bangkok File Services Co., Ltd. can provide the following important suggestions: 1 . Management should pay attention to the compensation, welfare and various benefits of Employee compensation is a great incentive for employees to be responsible. And work to be successful as well. 2. Executives should pay more attention to safety. Safety staff will work happily. No worries about danger Management should focus on opportunities to promote. It is an incentive. It is a morale boost for employees who are dedicated to working and dedicated to working.

\section{SUGGESTIONS FOR THE NEXT STUDY}

Qualitative research should be conducted in order to study the motivation factors of the employees of Bangkok File Services Co., Ltd. by in-depth interview method. To get a clear answer. This is a great way to improve the performance of Bangkok Lotte Service Co., Ltd. employees.

\section{REFERENCES}

[1] Tosaporn mahamud . (2558 B.E.: abstract) studied on "Opening Vittri fashion sunglasses business project kasembundit University, Bangkok"

[2] Sriplai Imsamran. (2554 B.E.: abstract). studied on "Consumer behavior on purchasing big eyescontact lens of college students at Cheatupon business college"

[3] Pantita Keawma. (2556 B.E.: abstract). studied on "Consumer behavior on purchasing glasses in Bang Rug, Bangkok"

[4] Jittaboon Jantapan. (2550 B.E.: abstract). studied on "Marketing mix factors correlated toconsumer behavior on buying glasses at department stores in Bangkok area."

[5] Terasak Pojananuparp. (2555 B.E.: abstract). Studied on "Marketing mix factors correlated toconsumer behavior on purchasing sunglasses in Bangkok 